\title{
The Research on The Synchronous Control System of Load-sensing Hydraulic Bending Machine
}

\author{
Xi Yang, Yuwan Cen, Xiaohua Ye and Jianzhong Huang \\ Anhui University of Technology, Maanshan, 243002, China
}

\begin{abstract}
As the energy consumption and the synchronous control precision of the large metal plate bending machine is undemanding currently, it employs load sensing and pressure compensation technique and constructs the AMESim model of synchronous control system in load sensing hydraulic bending machine, adopting PID to control it. The results of the simulating model show that synchronous control system of load sensing hydraulic bending machine can not only realize the synchronization of the asymmetrical piston system, but also improve the efficiency of the system.
\end{abstract}

Keywords-hydraulic bending machine; load-sensing pump; LUDV system; AMESim simulation; PID synchronous control

\section{INTRODUCTION}

With the increasing use of hydraulic technology in engineering field, synchronous control becomes a top priority if the loading ability of large equipment increases, the arrangement or when one working component need to be driven by more conducting components [1]. However, the leaking of each loop, friction and loading discrepancy in the hydraulic system cause the synchronous error of multiple execution structure. Besides, the cost of energy consumption boosts continually, it is in great need of designing a hydraulic synchronous control system of energy saving.

\section{The Design Of SynChronous CONTROL SyStem In LOAD SENSING HydRAulic BENDING Machine}

The schematic diagram of synchronous control system in load sensing hydraulic bending machine shown in figure 1.

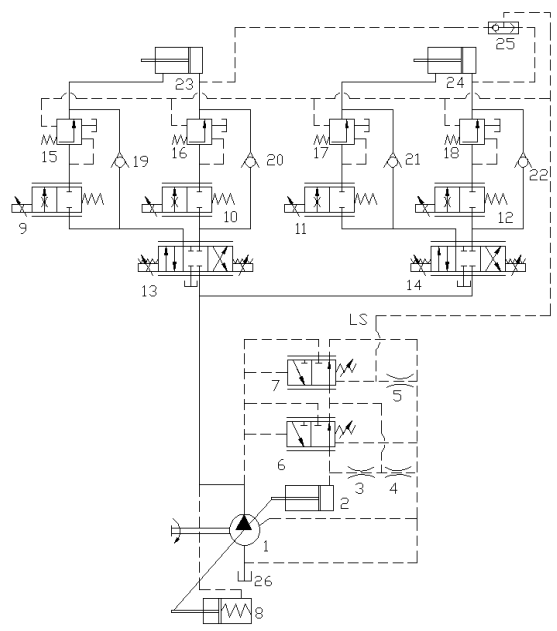

FIGURE I. THE SCHEMATIC DIAGRAM OF SYNCHRONOUS CONTROL SYSTEM IN LOAD SENSING HYDRAULIC BENDING MACHINE
Its main components are as follows: 1 . Variable pump; 2. Big cavity piston; 3.4.5. Throttle valve; 6. Constant pressure valve; 7. Load sensing valve; 8. Small cavity piston; 9.10.11.12. proportional throttle valve; 13.14. reversing valve; 15.16.17.18. pressure compensation valve; 19.20.21.22. check valve; 23.24. hydraulic cylinder; 25 . shuttle valve; 26 . fuel tank;

\section{A. The Operating Principle of Loading Sensing Variable Pump}

As shown in figure2, the loading sensing variable pump consists of load sensing valve, Constant pressure valve, variable cylinder sensitive cavity, variable cylinder spring cavity, adjustable restrictive valve. The distance of load sensing variable cylinder changes with the difference between the outlet pressure of oil pump and the loading pressure, then alters the pump swash-plate, outlet flow and pressure, which outputs the adaptive flow and pressure related to the load. The interaction of piston distance, system's pressure and flow variation forms the process of negative feedback control [2].

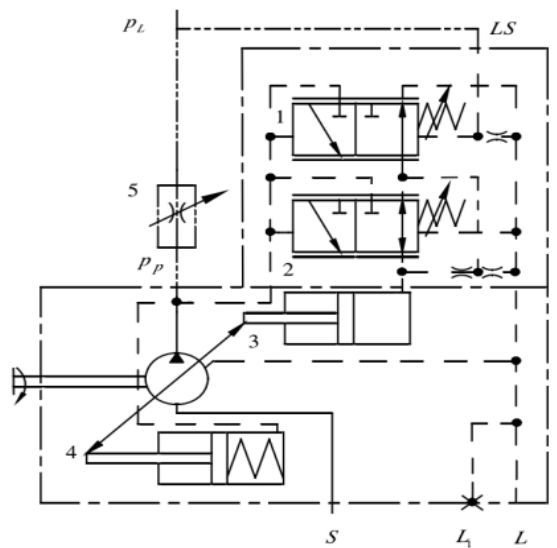

1.Load sensing piston 2. Constant pressure piston 3. variable cylinder sensitive cavity 4 . variable cylinder spring cavity 5 . adjustable restrictive valve

FIGURE II. SCHEMATIC DIAGRAM OF THE LOADING SENSING VARIABLE PUMP

B. The Principle of Dual-cylinder Synchronous Control LUDV System

As shown in figure 3 . Take load pressure $p_{1}>p_{2}$, then:

$$
\begin{gathered}
p_{m 1}-p_{1}=p_{k 1} \\
p_{m 2}-p_{1}=p_{k 2}
\end{gathered}
$$

If the set pressure of the two pressure compensation is equal, $p_{k 1}=p_{k 2}$, then $p_{m 1}=p_{m 2}$. 
Therefore, $\Delta p_{1}=\Delta p_{2}=\Delta p$

According to equation of throttle valve flow, the flow is:

$$
\begin{gathered}
Q_{v 1}=C_{1} A_{1} \sqrt{\frac{2 \Delta p}{\rho}} \\
Q_{v 2}=C_{2} A_{2} \sqrt{\frac{2 \Delta p}{\rho}}
\end{gathered}
$$

In the equation, $Q_{v 1}, Q_{v 2}$ the flow through throttle valve1,2( $L / \mathrm{min})$;

$$
C_{1}, C_{2}-\text { Flow constant; }
$$

$A_{1}, A_{2}$-area of throttle valve1,2( $\left.\mathrm{m}^{2}\right)$.

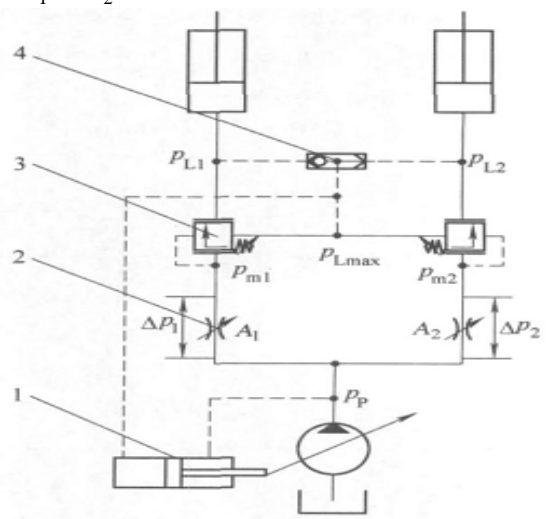

1.LS control valve 2. Orifice 3. Pressure compensation piston 4. Shuttle piston

\section{FIGURE III. PRINCIPLE OF LUDV SYSTEM}

The flow of hydraulic cylinder loop is only affected by throttle opening, and the controllability of LUDV is rather good. When the system is in a state of unsaturation, each hydraulic loop can work independently without interruption and realize compound action smoothly; when the system is in a state of saturation, it can still keep $\Delta p_{1}=\Delta p_{2}=\Delta p$, the flux flows through actuator will reduce proportionally, and each executive component will decrease its speed to achieve compound action at the same time [3].

\section{Modeling OF Synchronous CONTROL SySTEM IN LOAD SENSING HyRAulic BENDING Machine}

AMESim means the advanced modeling environment for simulations of engineering systems. AMESim, an excellent software put forward by IMAGIN company in 1995, specializes in the modeling, simulation in hydraulic and mechanic system, and dynamics analysis. It contains the special technique of IMAGIN and provides interactive ability for industrial design [4].

\section{A. AMESim Modeling and Simulation of Load Sensing Pump}

Figure 4 is the specialty testing system model of load sensing pump, set model parameter, motor speed:1500rev/min, the maximum opening of throttle valve: $6 \mathrm{~mm}$, the maximum pressure of proportional relief valve: 300bar, the maximum flow: $200 \mathrm{~mA}$, LS valve element's quality: $0.01 \mathrm{~kg}$,valve element's diameter: $6 \mathrm{~mm}$, spring stiffness: $24 \mathrm{~N} / \mathrm{mm}$, valve element's quality of constant pressure valve: $0.01 \mathrm{~kg}$, valve element's diameter: $6 \mathrm{~mm}$, spring stiffness: $50 \mathrm{~N} / \mathrm{mm}$, variable cylinder sensitive cavity: $24 \mathrm{~mm}$, variable cylinder spring cavity: $17 \mathrm{~mm}$, spring stiffness: $14 \mathrm{~N} / \mathrm{mm}$.

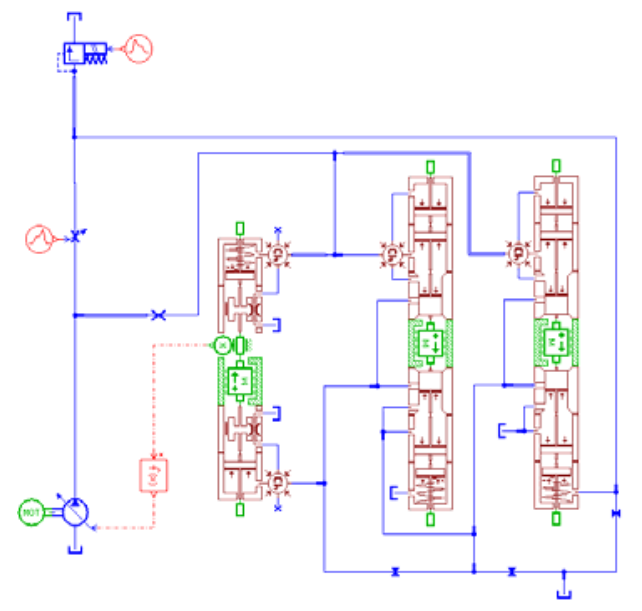

FIGURE IV. SPECIALTY TESTING SYSTEM MODEL OF LOAD SENSING PUMP

In order to verify the static characteristic curve of the pump, it sets the opening of throttle valve to $6 \mathrm{~mm}$ and turns the signal of proportional relief valve from 0 to $200 \mathrm{~mA}$, load pressure from 0 to $30 \mathrm{MPa}$. The sampling time is $0.001 \mathrm{~s}$, running simulation time $0.5 \mathrm{~s}$. the static characteristic curve of the pump flow pressure is shown in figure 5. Figure 6 is the static characteristic curve of Rexroth A10VSO45DFR1 sample. The two are basically coincided with each other after comparison.

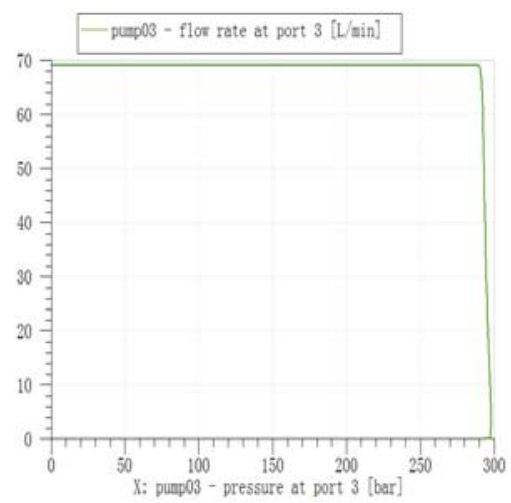

FIGURE V. THE STATIC CHARACTERISTIC CURVE OF THE PUMP FLOW PRESSURE

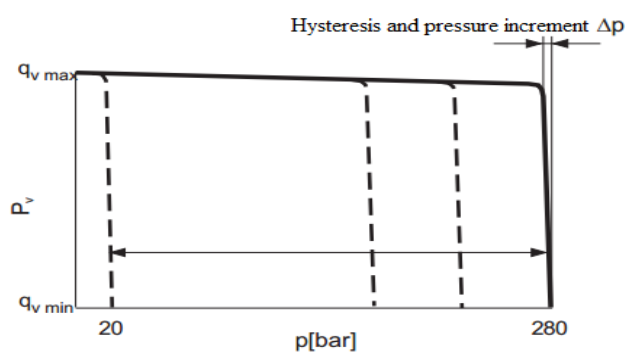

FIGURE VI. THE STATIC CHARACTERISTIC CURVE OF REXROTH A10VSO45DFR1 SAMPLE 
In order to verify the dynamic characteristic curve of the model, it needs to send a setting signal of $186 \mathrm{~mA}$ to relief valve and a square signal to throttle signal, which then receives the dynamic characteristic simulating curve of flow control. Figure8 is the dynamic characteristic simulating curve of Rexroth A10VSO45DFR1 sample flow control. When the load pressure is 280 bar, its positive step responsive time is $45 \mathrm{~ms}$, negative step responsive time $20 \mathrm{~ms}$, while the positive step responsive time of the sample is $50 \mathrm{~ms}$, negative step responsive time $25 \mathrm{~ms}$. The two are almost the same. In conclusion, the AMESim modeling is basically right.

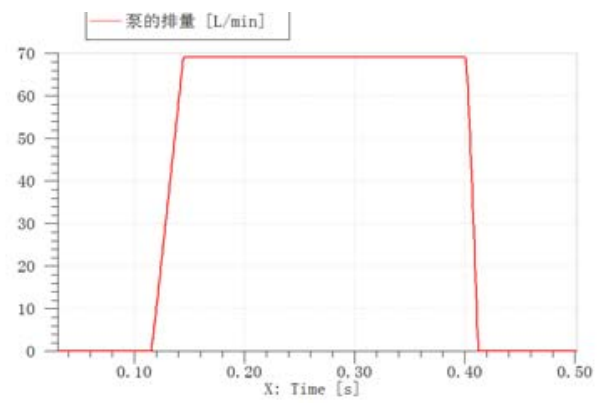

FIGURE VII. THE DYNAMIC CHARACTERISTIC SIMULATING CURVE OF FLOW CONTROL

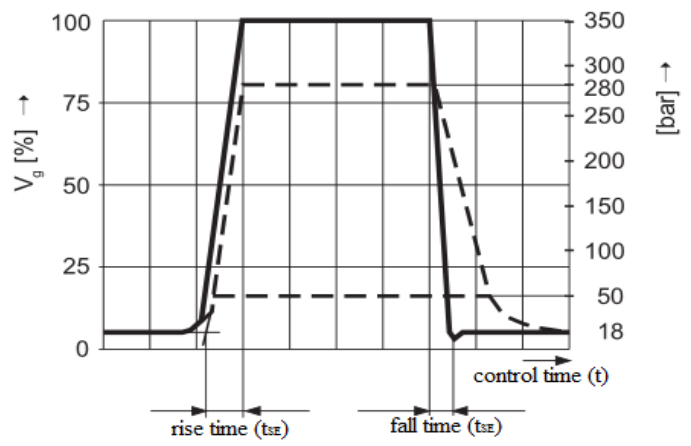

FIGURE VIII. THE DYNAMIC CHARACTERISTIC SIMULATING CURVE OF REXROTH A10VSO45DFR1 SAMPLE FLOW CONTROL

B. Overall Modeling and Simulation of Synchronous Control System in Load Sensing Hydraulic Bending Machine

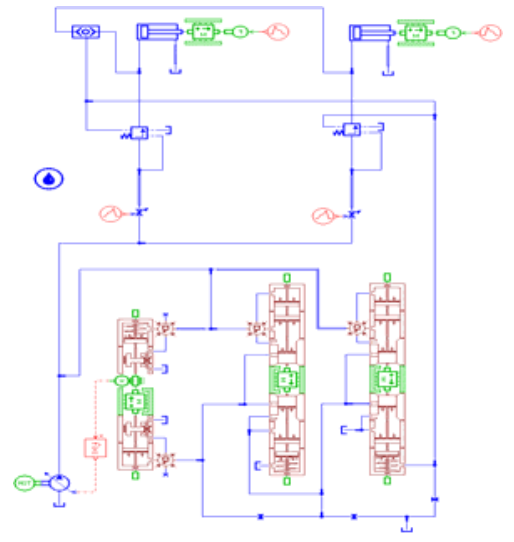

FIGURE IX. OVERALL MODELING OF SYNCHRONOUS CONTROL SYSTEM IN LOAD SENSING HYDRAULIC BENDING MACHINE
It keeps each component parameter of load sensing variable pump unchangeable to simulate figure 9 , setting the differential pressure of pressure compensation valve as 10bar; simulation load quality as $700 \mathrm{~kg}$; sampling time as $0.01 \mathrm{~s}$, under running mode; running simulation time as $8 \mathrm{~s}$.

1) the changing curve of load pressure and the changing opening curve of proportional throttle valve is shown in figure 10 and figure 11 . When simulating it reaches the changing curve of system's pressure and flow, as you can see in figure 12 and figure 13. Figure 10: changing curve of the two input load pressure; Figure 11: changing curve of the two proportional throttle valve opening; Figure 12: changing curve of the system's pressure; Figure 13: changing curve of the system's flow.

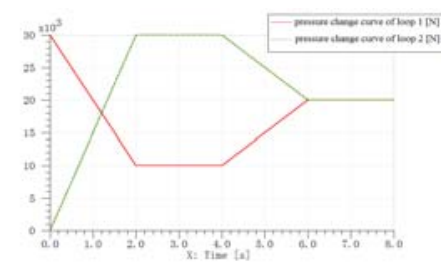

FIGURE X. CHANGING CURVE OF THE TWO INPUT LOAD PRESSURE

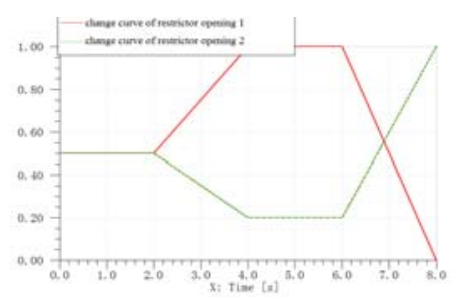

FIGURE XI. CHANGING CURVE OF THE TWO PROPORTIONAL THROTTLE VALVE OPENING

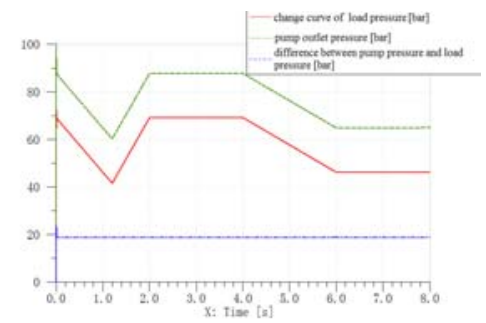

FIGURE XII. CHANGING CURVE OF THE SYSTEM'S PRESSURE

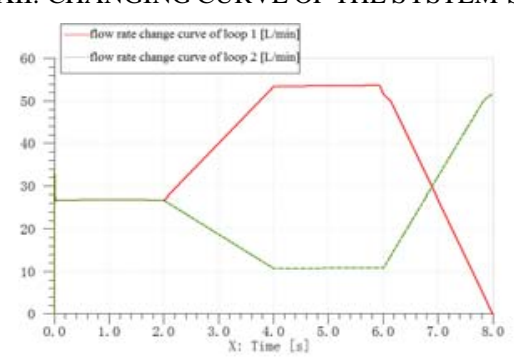

FIGURE XIII. CHANGING CURVE OF THE SYSTEM'S FLOW

As shown in figure 11,12,13,14, the flow of the two loops is proportional to the opening of each proportional throttle valve, while the load has no effects on the flow of the two loops. The error between pump's outlet pressure and the 
maximum pressure of the two loops is constant, which is about 1.8MPa.

2) when the system is in a state of saturation, it sets the motor's speed as 1000rev/min , which achieves the changing curve of the two load pressure and the changing curve of proportional throttle valve as in figure 10 and figure 11 . Then it simulates and reaches the changing curve of the system's pressure and flow as in figure 14 and 15.

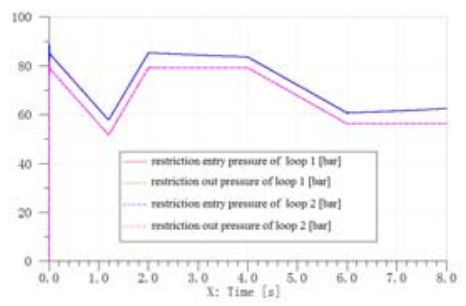

FIGURE XIV. THE SYSTEM'S PRESSURE

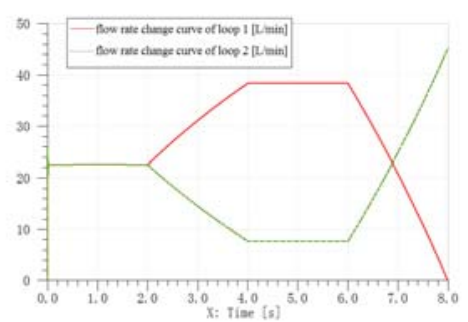

FIGURE XV. THE SYSTEM'S FLOW

As shown in figure 14 and figure 15, when the system is in a state of saturation, it can keep $\Delta p_{1}=\Delta p_{2}=\Delta p$ and distribute flux proportionally to each loop according to the opening of throttle valve, rather than flow to the loop of low load.

\section{Analyzing The Factors Affect The Precision Of SYNCHRONOUS CONTROL SYSTEM IN LOAD SENSING HYDRAULIC BENDING MACHINE}

When setting the opening of each throttle valve of the two loops as 3mm, it reaches the changing curve of load in the two loops as in figure16. It sets the sampling time as $0.01 \mathrm{~s}$; running simulating time as $5 \mathrm{~s}$.

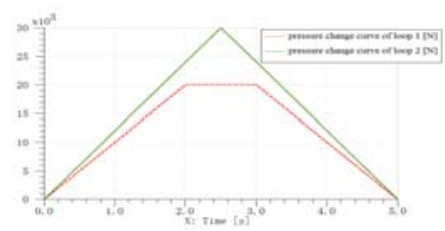

\section{FIGURE XVI. CHANGING CURVE OF THE LOAD IN THE TWO LOOPS}

\section{1) The affects of the system leakage}

Take the leakage of the two hydraulic cylinder as $0.095 \mathrm{~L} / \mathrm{min} / \mathrm{bar}, 00.1 \mathrm{~L} / \mathrm{min} / \mathrm{bar}$, then the displacement changing curve of the two hydraulic cylinders and the difference of the displacement variation between the two hydraulic cylinders can be shown in figure 17 and figure 18.

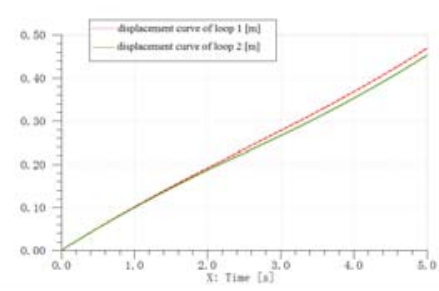

FIGURE XVII. THE DISPLACEMENT CHANGING CURVE OF THE TWO HYDRAULIC CYLINDERS

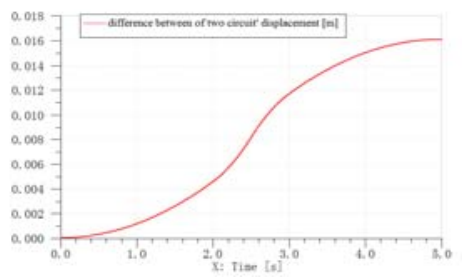

FIGURE XVIII. THE DIFFERENCE OF THE DISPLACEMENT VARIATION BETWEEN THE TWO HYDRAULIC CYLINDERS

As shown in figure 18, with the increase of the pressure, the leakage adds too. Even the technical parameters of the two hydraulic cylinders and hydraulic loop are the same, it can not guarantee identical leakage of the two loops. After a long term operation of the system, the function of each component changes a lot, and its leakage is hard to control.

2) Affects of Pipe Resistance

Take the diameter of one oil tuba as $25 \mathrm{~mm}$, and another one as $15 \mathrm{~mm}, 25 \mathrm{~mm}, 35 \mathrm{~mm}, 45 \mathrm{~mm}$, then simulate it, difference of displacement changing curve of the two hydraulic cylinders is shown in figure 19.

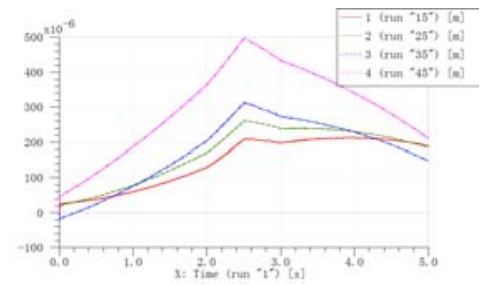

FIGURE XIX. AFFECTS OF TWO-CYLINDERS SYNCHRONIZATION WITH DIFFERENT OIL TUBE DIAMETERS

Take oil tube length of one loop as $1 \mathrm{~m}$, another as $1 \mathrm{~m}, 2 \mathrm{~m}$, $3 \mathrm{~m}, 4 \mathrm{~m}$, then simulate it to achieve the difference of displacement changing curve of two hydraulic cylinders, As shown in figure 20.

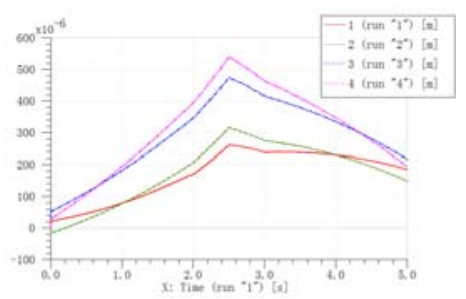

FIGURE XX. AFFECTS OF TWO-CYLINDERS SYNCHRONIZATION WITH DIFFERENT OIL TUBE LENGTHS

As shown in figure 19 and figure 20, length and diameter of oil tube can create resistance to the flow of liquid, liquid 
will be affected by one-way resistance in the procedure of homogeneous flow and local resistance in the inlet and outlet of pipeline and pipe bend. As different oil tube length, diameter and bending will meet different resistance, which will affect its running speed to generate synchronous error.

\section{3) Affects of Gas Content in Hydraulic oil}

Take gas content in hydraulic oil as $0.1 \%, 0.3 \%, 0.5 \%, 0.7 \%$, then simulate it to gain the difference of displacement changing curve of two hydraulic cylinder, as shown in figure 21.

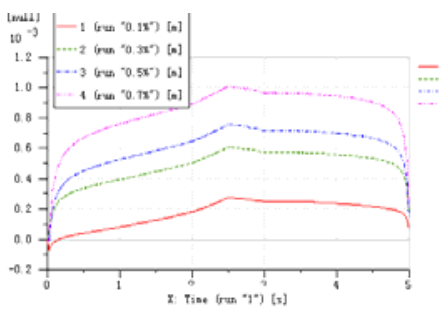

FIGURE XXI. AFFECTS OF HYDRAULIC SYNCHRONOUS SYSTEM WITH DIFFERENT GAS CONTENT IN HYDRAULIC

As shown in figure 21, the higher the gas content in hydraulic oil, the bigger the synchronous error is. The air in hydraulic oil can be divided into two kinds: entrapped air and dissolved air. When the pressure increases, dissolved air in hydraulic oil increases; when the pressure decreases, the entrapped air in hydraulic oil increases. Air in hydraulic oil will change the compression rate, affect its running speed and displacement to cause synchronous error.

4) Affects of Mixed Impurity in Hydraulic Oil

When there are mixed impurities in hydraulic oil, it will change the flow in the loop and give rise to different running movement velocities in different loops to cause synchronous error. Besides mixed impurity affects the compression, heat conduction and lubrication of hydraulic oil.

\section{5) Affects of Pressure Surge}

Change of pressure difference in orifice and pump outlet pressure will affect system synchronization. Pressure surge will cause fluctuation, noise and flow surge to reduce the precision of system synchronization.

6) Affects of Oil Temperature

Take system's temperature as 5C, 50C, 75C, then simulate it to achieve difference of displacement changing curve of the two hydraulic cylinders, as shown in figure 22.

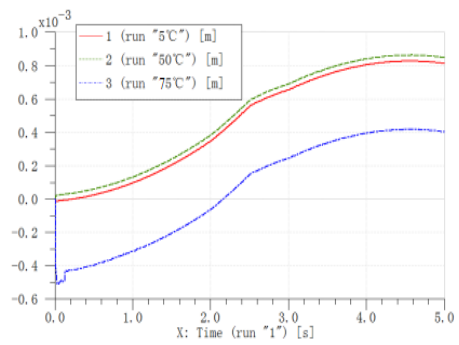

FIGURE XXII. AFFECTS OF HYDRAULIC SYSTEM SYNCHRONIZATION WITH CHANGING TEMPERATURES.
As shown in figure 22, when the temperature is not too high, it shows little affectation to synchronization. With the operation increases, temperature will add, oil's viscidity reduces and leakage of the system increases, which will cause precision of synchronous control.

\section{Pid Control To LoAd SENSING Hydraulic BENDING MACHINE SYNCH-RONOUS CONTROL}

As affected by different leakage, resistance in each loop and air content in hydraulic oil, it reduces precision of synchronous control. The system adopts pressure compensation technique to improve its precision of synchronous control, using displacement sensor of high precision to test each cylinder displacement and compare its difference. It employs control algorithm, adjusting its opening of proportional valve to achieve synchronous control. We adopt PID master slave control method to adjust the system, as shown in figure 23.

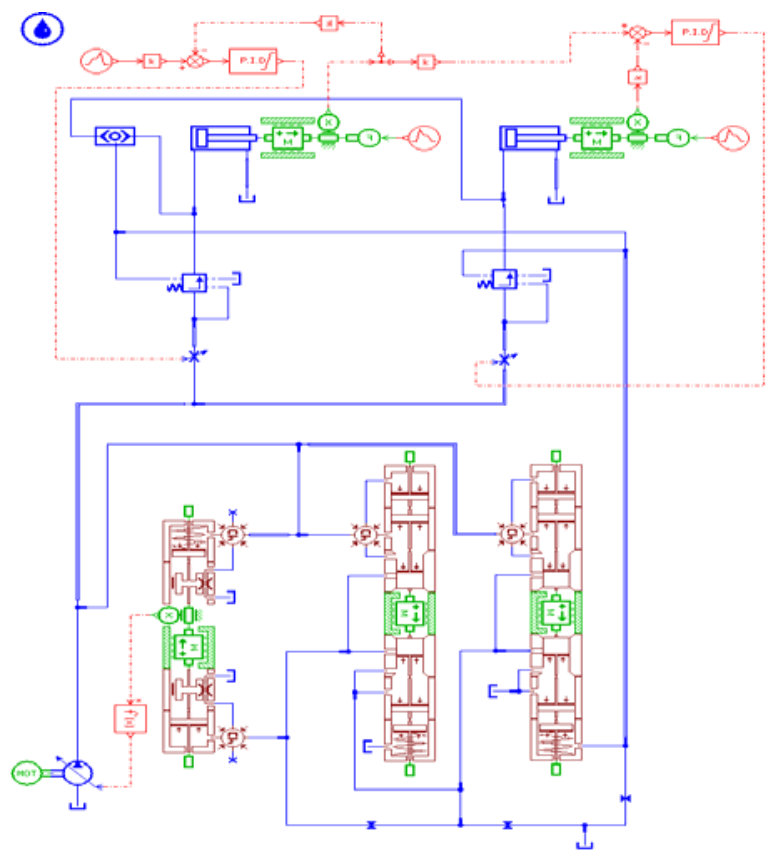

FIGURE XXIII. PID CONTROL SCHEMATIC DIAGRAM OF LOAD SENSING HYDRAULIC BENDING MACHINE SYNCHRONOUS CONTROL

PID controller is a control method, which is widely used in process control [5]. Setting of PID controller parameter refers to some related references [6]. The final result is $\mathrm{P}=6.6 、 \mathrm{I}=47 、 \mathrm{D}=0.011$.

Take leakage of the two loops as $0.095 \mathrm{~L} / \mathrm{min} / \mathrm{bar}$, $0.1 \mathrm{~L} / \mathrm{min} / \mathrm{bar}$, load pressure as $20 \mathrm{KN}, 30 \mathrm{KN}$, give a value-added of 0.1 step function , take sampling time as $0.01 \mathrm{~s}$, running simulation time as $5 \mathrm{~s}$ under executive mode. Simulation results are shown in figure 24 and figure 25 . Figure 24: Difference of displacement changing curve of two-cylinders;Figure 25: Difference of displacement changing curve of two-cylinders' drawing of partial enlargement. 


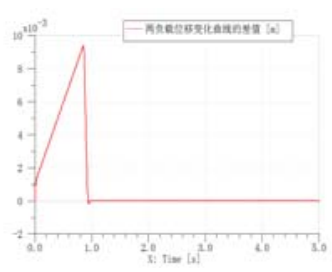

FIGURE XXIV. DIFFERENCE OF DISPLACEMENT CHANGING CURVE OF TWO-CYLINDERS

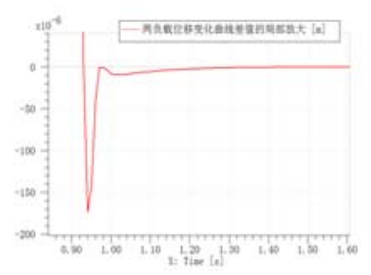

FIGURE XXV. DIFFERENCE OF DISPLACEMENT CHANGING CURVE OF TWO-CYLINDERS’ DRAWING OF PARTIAL ENLARGEMENT

As shown in figure 24 and figure 25, two orifices are wholly open in the beginning phase, two-cylinders synchronous error reaches its maximum in $0.85 \mathrm{~s}$ with different discharges of two-cylinders. It uses $0.12 \mathrm{~s}$ for two-cylinders synchronous error to reduce its maximum difference to zero, which can meet engineering requirements within $\pm 0.1 \times 10^{-3} \mathrm{~mm}$ after stabilization.

\section{CONCLUSION}

Load sensing hydraulic bending machine synchronous control adopts load sensing and pressure compensation technology to increase its efficiency by matching its needed pressure and pumping source pressure flow, also each looping flow in the system will not be affected by the changing load, then using PID control to effectively realize the synchronization of unsymmetrical cylinder.

\section{REFERENCES}

[1] Donghai Su: Hydraulic Synchronous Control System And Its Application[J], Journal of Shen Yang University of Technology, 2005,27(4): 364-367.

[2] Huiyu Shi, Bo Liu: Simulation of Load Sensing Hydraulic Synchronous Control System Based on AMESim[J], Hydraulic Pneumatic And Seal, 2011, (3):23.

[3] Zhenyuan Mao: Control Schematic Analysis And Application Of PID In Rotary Drilling Rig[J]. Engineering Machinery Abstract, 2014.1.

[4] Donghai Su, Jianghua Yu: New Technology Of Hydraulic Simulation AMESim And Application[J]. 2006,33(11):35.

[5] Zhi Yang, Haifeng Zhu, Yihua Huang: Design Of PID Controller And Parameter Setting Methods Summary[D]. Chemical Process Automation And Instrument, 2005,32 (5):1-7.

[6] Zhiqiang He: PID Control Parameter Setting Methods And Its Application Research[D], Hangzhou: Zhejiang University, 2005. 